\title{
Lifetime use of psychiatric medications and cognition at 43 years of age in schizophrenia in the Northern Finland Birth Cohort 1966
}

\author{
Hulkko, A. P.
}

2017-09

Hulkko , A P , Murray , G K, Moilanen , J , Haapea , M , Rannikko , I , Jones , P B , Barnett , J H , Huhtaniska , S , Isohanni , M K , Koponen , H , Jaaskelainen , E \& Miettunen , J 2017 , ' Lifetime use of psychiatric medications and cognition at 43 years of age in schizophrenia in the Northern Finland Birth Cohort 1966 ' , European Psychiatry , vol. 45 , pp. 50-58 . https://doi.org/10.1016/j.eurpsy

http://hdl.handle.net/10138/298128

https://doi.org/10.1016/j.eurpsy.2017.06.004

publishedVersion

Downloaded from Helda, University of Helsinki institutional repository.

This is an electronic reprint of the original article.

This reprint may differ from the original in pagination and typographic detail.

Please cite the original version. 
Original article

\title{
Lifetime use of psychiatric medications and cognition at 43 years of age in schizophrenia in the Northern Finland Birth Cohort 1966
}

\author{
A.P. Hulkko ${ }^{\text {a,b,c,* }}$, G.K. Murray ${ }^{\text {d,e }}$, J. Moilanen ${ }^{\text {a,b,c }}$, M. Haapea ${ }^{\text {b,f,g }}$, I. Rannikko ${ }^{\text {b,f }}$, P.B. Jones ${ }^{\text {h }}$, \\ J.H. Barnett ${ }^{\mathrm{d}, \mathrm{i}}$, S. Huhtaniska ${ }^{\mathrm{a}, \mathrm{b}, \mathrm{f}}$, M.K. Isohanni ${ }^{\mathrm{f}}$, H. Koponen ${ }^{\mathrm{j}}$, E. Jääskeläinen ${ }^{\mathrm{a}, \mathrm{b}, \mathrm{c}, \mathrm{f}}$, \\ J. Miettunen b,f
}

${ }^{a}$ Department of Psychiatry, Research Unit of Clinical Neuroscience, University of Oulu, P.O. Box 5000, 90014, Oulu, Finland

${ }^{\mathrm{b}}$ Medical Research Center Oulu, Oulu University Hospital and University of Oulu, Oulu, Finland

${ }^{\mathrm{c}}$ Department of Psychiatry, Oulu University Hospital, P.O. Box 26, 90029 OYS, Oulu, Finland

${ }^{\mathrm{d}}$ Department of Psychiatry, Addenbrooke's Hospital, University of Cambridge, Box 189, CB2 0QQ Cambridge, United Kingdom

${ }^{\mathrm{e}}$ Behavioural and Clinical Neuroscience Institute, University of Cambridge, Herchel Smith Building, Forvie Site, Cambridge Biomedical Campus, CB2 0SZ

Cambridge, United Kingdom

${ }^{\mathrm{f}}$ Center for Life Course Health Research, University of Oulu, P.O. Box 5000, 90014 Oulu, Finland

${ }^{\mathrm{g}}$ Department of Diagnostic Radiology, Oulu University Hospital, P.O. Box 50, 90029 OYS, Oulu, Finland

${ }^{\mathrm{h}}$ Department of Psychiatry, University of Cambridge, Herchel Smith Building, CB2 OSZ Cambridge, United Kingdom

${ }^{i}$ Cambridge Cognition Ltd, Tunbridge Court, Bottisham, Cambridge, United Kingdom

${ }^{\mathrm{j}}$ Psychiatry Department, University of Helsinki and Helsinki University Hospital, P.O. Box 22, 00014 Helsinki, Finland

\section{A R T I C L E I N F O}

\section{Article history:}

Received 27 April 2017

Received in revised form 7 June 2017

Accepted 11 June 2017

Available online 27 June 2017

\section{Keywords:}

Schizophrenia

Cognition

Benzodiazepine

Antidepressant

Antipsychotic

Polypharmacy

\begin{abstract}
A B S T R A C T
Background: Higher lifetime antipsychotic exposure has been associated with poorer cognition in schizophrenia. The cognitive effects of adjunctive psychiatric medications and lifetime trends of antipsychotic use remain largely unclear. We aimed to study how lifetime and current benzodiazepine and antidepressant medications, lifetime trends of antipsychotic use and antipsychotic polypharmacy are associated with cognitive performance in midlife schizophrenia.

Methods: Sixty participants with DSM-IV schizophrenia from the Northern Finland Birth Cohort 1966 were examined at 43 years of age with an extensive cognitive test battery. Cumulative lifetime and current use of psychiatric medications were collected from medical records and interviews. The associations between medication and principal component analysis-based cognitive composite score were analysed using linear regression.

Results: Lifetime cumulative DDD years of benzodiazepine and antidepressant medications were not significantly associated with global cognition. Being without antipsychotic medication (for minimum 11 months) before the cognitive examination was associated with better cognitive performance $(P=0.007)$ and higher lifetime cumulative DDD years of antipsychotics with poorer cognition $(P=0.020)$, when adjusted for gender, onset age and lifetime hospital treatment days. Other lifetime trends of antipsychotic use, such as a long antipsychotic-free period earlier in the treatment history, and antipsychotic polypharmacy, were not significantly associated with cognition.

Conclusions: Based on these naturalistic data, low exposure to adjunctive benzodiazepine and antidepressant medications does not seem to affect cognition nor explain the possible negative effects of high dose long-term antipsychotic medication on cognition in schizophrenia.
\end{abstract}

(c) 2017 Elsevier Masson SAS. All rights reserved.

\footnotetext{
* Corresponding author. Department of Psychiatry, Research Unit of Clinical Neuroscience, University of Oulu, P.O. Box 5000, 90014 Oulu, Finland. Fax: +3588336169 .

E-mail address: anja.husa@student.oulu.fi (A.P. Hulkko).
}

\section{Introduction}

Antipsychotic medication forms the foundation of the evidence-based pharmacological treatment of schizophrenia $[1,2]$. Antipsychotic polypharmacy, defined as the concomitant use of 2 or more antipsychotics, and other psychiatric medications, such as benzodiazepines and antidepressants, are also widely used 
in schizophrenia, especially in case of incomplete treatment response or comorbid psychiatric symptoms, although their indications and efficacy are less clear [3-5]. Neurocognitive deficits are a central dimension of schizophrenia, emerging during deviant neurodevelopment [6], being established by the first psychotic episode and staying relatively stable during the illness course for up to 10 years [7-9] and also in older persons with schizophrenia [10]. Because of the key role of these deficits in influencing the long-term outcome in schizophrenia [11], it is important to study the safety and effects of medication on cognition.

Antipsychotics have been associated with mild to moderate, positive cognitive effects in short-term randomised, controlled trials (RCTs) [12-14], possibly mostly explained by practice effects [15]. Very little is known of the long-term cognitive effects of antipsychotics in schizophrenia after 2-3 [16] or 5 years of use [17]. In naturalistic studies, higher antipsychotic doses [18-20] or antipsychotic polypharmacy [19] have been associated with poorer cognition, and dose-reduction with improved cognition $[21,22]$.

Benzodiazepines are used by patients with schizophrenia for sedation, to treat anxiety and agitation or to combat adverse effects of antipsychotics [23]. There is no evidence of efficacy against psychotic symptoms [24] and there are concerns about the long-term safety of benzodiazepines, which have been associated with higher mortality in schizophrenia [23,25]. Longterm use of benzodiazepines (mean 10 years) has been associated with cognitive impairment in a meta-analysis [26]. In schizophrenia cognitive improvement has been reported after the reduction of long-term (mean 4-11 years) benzodiazepine use $[27,28]$.

Antidepressants have some efficacy in reducing depressive [29] and negative [30] symptoms in schizophrenia, and moderate to high antidepressant exposure has been linked to lower mortality [25]. The cognitive effects of antidepressants in schizophrenia, studied in clinical trials ranging from 4 to 24 weeks in duration, have been positive, but clinically non-significant in one recent meta-analysis [31] and review [32].

The long-term effects of psychiatric medications in schizophrenia are mostly unknown. Studies on the lifetime use of psychiatric medications are rare and limited to antipsychotic medication largely ignoring other psychiatric medications. Double-blind RCTs of long-term treatment are the golden standard for the study of treatment effects, but difficult to carry out for several years. Naturalistic, observational samples offer a feasible setting to investigate the long-term effects of medication [33] and form at least hypotheses for further study.

Pharmacoepidemiology has been a major study arm of the Northern Finland Birth Cohort 1966 (NFBC 1966) [34]. We previously showed that higher lifetime cumulative doses of antipsychotic medication were associated with a decline in verbal learning and memory between ages 34 and 43 years [17] and poorer global cognitive performance at the age of 43 years in schizophrenia [16]. However, prior research, including our own, has mainly focused on associations between cognition and antipsychotic medication, and we have not fully considered the possible effects of other psychotropic medication. In this study therefore, we aimed to investigate, for the first time, how lifetime cumulative and cross-sectional doses of benzodiazepine and antidepressant medications are associated with cross-sectional, global cognition in schizophrenia at 43 years of age. We also wanted to probe the effects of lifetime use of antipsychotics, and especially antipsychotic polypharmacy, on cognition in more detail than in our previous studies. We hypothesised that higher benzodiazepine and antipsychotic use, and antipsychotic polypharmacy, would be associated with poorer cognition and antidepressant use with neutral or positive cognitive effects, when potential confounders were taken into account.

\section{Methods}

\subsection{Sample}

\subsubsection{Participants}

The participants were derived from the unselected, general population-based Northern Finland Birth Cohort 1966 (NFBC 1966) that consists of 12,058 live-born children [35]. The NFBC 1966 members with a lifetime psychosis diagnosis were detected from national register data by the end of 2008 and questionnaire data collected in 1997 [36]. Persons with a psychosis diagnosis in the Care Register for Health Care, in the Social Insurance Institution of Finland registers on sick leaves, disability pensions or the right to reimbursement for psychoactive medication due to psychosis and those who reported a psychosis or current antipsychotic use were included.

This procedure, described in more detail in our earlier work [16], resulted in 257 NFBC 1966 members with a lifetime psychosis diagnosis and known address, who were invited. Ninety-nine persons (38.5\%) participated in a psychiatric examination in 2008-2011 including the SCID I interview leading to DSM-IV lifetime diagnosis. There were 60 (87.0\%) persons with a diagnosis of schizophrenia spectrum disorder, a completed cognitive test battery and information on lifetime antipsychotic medication. Of them 50 (83\%) had a DSM-IV lifetime diagnosis of schizophrenia, 6 (10\%) schizoaffective, 2 (3\%) schizophreniform and 2 (3\%) delusional disorder. In this article, hereafter, the term schizophrenia encompasses schizophrenia and other schizophrenia spectrum disorders. Lifetime antipsychotic dose and cognition at 43 years of age has been studied in this same sample before [16] and a subsample of it (40 cases, 67\%) was analysed in another study on lifetime antipsychotic medication and change of verbal learning and memory between 34 and 43 years [17].

There was selective attrition of participants in educational level, onset age, disability pension status and schizophrenia diagnosis, but weighted sensitivity analyses performed in an earlier study of this sample [16] confirmed that attrition did not significantly affect the results on cumulative lifetime antipsychotic medication dose and global cognition at age 43 years.

\subsubsection{Ethical considerations}

The Ministry of Social and Health Affairs gave permission to collect data for the NFBC 1966 study. The Ethical Committee of the Northern Ostrobothnia Hospital District regularly reviews the study. All participants gave informed consent. The Code of Ethics of the World Medical Association (Declaration of Helsinki) for experiments involving humans was followed.

\subsection{Data on psychiatric medication}

Information on the lifetime use of psychiatric medications until the 43-year examination date was collected during 2007-2016 from all available Finnish hospital and outpatient records. Data collection of antipsychotic medication, described in detail elsewhere [17,37], was completed in 2014 and collection of other psychiatric medications in 2016. These data were supplemented with information on current (last 3 months) and earlier use of psychiatric medications obtained in an interview in the 43-year study [38] and register of the Social Insurance Institution of Finland on psychoactive medications purchased in 1997. Based on this information the cumulative lifetime and current doses of psychiatric medications were calculated. 


\subsection{Neurocognitive assessment}

The neuropsychological examination was performed at the 43year study using an extensive neuropsychological battery of tests comprising the Abstraction Inhibition and Working Memory task (AIM) [39], California Verbal Learning Test (total scores of trials 15; CVLT) [40], Visual Object Learning Test (VOLT) [41], Verbal fluency [42], Visual series (WMS-III) [43], and Vocabulary, Digit Span and Matrix reasoning (WAIS-III) [44].

\subsection{Variables}

\subsubsection{Neurocognitive variables and the cognitive composite score}

A principal component analysis (PCA) of the eight chosen neurocognitive test variables resulted in a cognitive composite score representing global cognitive performance (see 2.5 Statistical analyses) [16].

\subsubsection{Medication variables}

The psychiatric medications were classified according to the Anatomical Therapeutic Chemical (ATC) classification system [45] into benzodiazepines (including benzodiazepine derivatives N05BA, N03AE and N05CD; and benzodiazepine related drugs N05CF), antidepressants (N06A), antipsychotics (N05A), anticholinergic agents (N04A) and other psychiatric medication.

The medication variables representing lifetime and current use are described in detail in Table 1 . The current doses were transformed to Defined Daily Dose ratios (DDD ratios) and cumulative exposure to Defined Daily Dose years (DDD years) [45].

\subsubsection{Background variables}

The analyses were adjusted for relevant background variables and confounders, including gender, age of illness onset, markers of severity of illness (logarithmic transformation of cumulative lifetime psychiatric hospital treatment days until the study, and remission and PANSS positive, negative and disorganisation symptoms, classified based on the factor structure described by van der Gaag et al. [46], at the time of the study), educational level (Supplementary material, Methods) and current antipsychotic dose and benzodiazepine and antidepressant use (Table 1).

\subsection{Statistical analyses}

The measure of global cognitive performance was derived from a PCA of the cognitive test variables (Immediate free recall of trials 1-5 of CVLT, total scores of VOLT, AIM, Verbal fluency, Visual series, Vocabulary, Digit Span and Matrix reasoning). Missing values of the cognitive tests (one case was missing an AIM score, 2 a VOLT score and 3 both VOLT and AIM scores) were predicted using multiple imputation (20 datasets) [47] with fully conditional specification (MCMC) method and linear regression as model type using data from all eight cognitive test variables. The PCA (eigenvalue set as $>1$ ) resulted in one cognitive factor (cognitive composite score), which explained $52.9 \%$ of total variance. Communalities were between 0.32 and 0.66 and factor loadings between 0.57 and 0.81 .

The associations between the cognitive composite score and psychiatric medication variables were analysed using linear regression analysis. The natural logarithm of DDD years of lifetime psychiatric medications to correct for their skewness and nontransformed other psychiatric medication variables were used as predictor variables. The effects of medication variables in the linear regression models are presented as unstandardised regression coefficients (B) and their standard error (SE), standardised regression coefficients (Beta) and $P$-values. As post hoc analyses, the means of the composite score with $95 \%$ confidence intervals were plotted in the high-, medium- and low-dose groups of the cumulative DDD years of medication (divided based on tertiles). $P$ values $<0.05$ were considered statistically significant. The analyses were performed using IBM SPSS Statistics 24 [48].

\section{Results}

\subsection{The characteristics of the sample}

The characteristics of the sample are described in Table 2. The sample consisted of 60 cases (33 males, 55\%) with lifetime schizophrenia. The mean duration of illness of the sample was 16.5 years (SD 6.0) and average age was 43.1 years (SD 0.8).

Table 1

Descriptions of the psychiatric medication variables.

\begin{tabular}{|c|c|}
\hline Name of the variable & Description of the variable \\
\hline \multicolumn{2}{|l|}{ Lifetime cumulative dose } \\
\hline Lifetime DDD years of benzodiazepines & $\begin{array}{l}\text { A sum of DDDs of benzodiazepine medications the person had used, divided by } 365.25 \text { days, i.e. exposure to } \\
\text { medication that corresponds using one defined daily dose per day for a year }\end{array}$ \\
\hline Lifetime DDD years of antidepressants & A sum of DDDs of antidepressant medications the person had used, divided by 365.25 days \\
\hline Lifetime DDD years of antipsychotics & A sum of DDDs of antipsychotic medications the person had used, divided by 365.25 days \\
\hline \multicolumn{2}{|l|}{ Current psychiatric medication } \\
\hline Current DDD ratio of benzodiazepines & The daily dose of benzodiazepines the person used at the time of the study divided by their DDD \\
\hline Current DDD ratio of antidepressants & The daily dose of antidepressants the person used at the time of the study divided by their DDD \\
\hline Current DDD ratio of antipsychotics & The daily dose of antipsychotics the person used at the time of the study divided by their DDD \\
\hline Current use of benzodiazepines & Use of benzodiazepines at the time of the study (yes/no) \\
\hline Current use of antidepressants & Use of antidepressants at the time of the study (yes/no) \\
\hline Current antipsychotic polypharmacy & Concomitant use of two or more antipsychotic medications at the time of the study (yes/no) \\
\hline \multicolumn{2}{|l|}{ Trends of lifetime use of antipsychotic medication } \\
\hline Proportion of time with antipsychotic use & $\begin{array}{l}\text { Proportion of time during which antipsychotic medication was used of the whole duration of illness }{ }^{\mathrm{a}} \\
\left.\left.\left.\text { classified into three categories }{ }^{\mathrm{b}}: 1\right)<50 \%, 2\right) 50-95 \%, 3\right)>95 \% \text { of time }\end{array}$ \\
\hline Long antipsychotic-free periods during treatment & $\begin{array}{l}\text { Having one or more periods of at least one year without antipsychotic medication since the start of } \\
\text { antipsychotic treatment (yes/no), but use of antipsychotics during the cognitive examination }\end{array}$ \\
\hline $\begin{array}{l}\text { Being without antipsychotic medication before } \\
\text { the cognitive examination }\end{array}$ & $\begin{array}{l}\text { Having a break in antipsychotic medication at least } 3 \text { months before and during the cognitive examination } \\
\text { (yes/no) }\end{array}$ \\
\hline Proportion of time on antipsychotic polypharmacy & $\begin{array}{l}\text { Proportion of time with concomitant use of two or more antipsychotic medications of the entire time during } \\
\left.\left.\text { which antipsychotic medication was used classified into three classes }{ }^{\mathrm{b}}: 1\right)<5 \%, 2 \text { ) } 5-40 \%, 3\right)>40 \% \text { of time }\end{array}$ \\
\hline
\end{tabular}

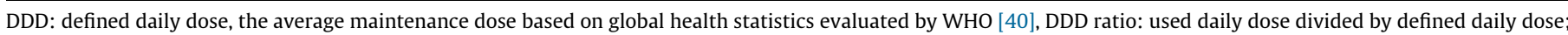
DDD year: exposure to medication that corresponds using one defined daily dose per day for a year.

a Duration of illness = time since the onset of illness or first psychiatric medication.

b The classes were chosen based on distribution of the data. 
Table 2

Characteristics of the sample.

\begin{tabular}{|c|c|}
\hline & Schizophrenia \\
\hline \multicolumn{2}{|l|}{ Sociodemographic factors } \\
\hline \multicolumn{2}{|l|}{ Sex, $n(\%)$} \\
\hline Males & $33(55 \%)$ \\
\hline \multicolumn{2}{|l|}{ Education, $n(\%)^{\mathrm{a}}$} \\
\hline Low & $33(56 \%)$ \\
\hline Middle & $15(25 \%)$ \\
\hline High & $11(19 \%)$ \\
\hline \multicolumn{2}{|l|}{ Occupational status, $n(\%)$} \\
\hline Working & $18(30 \%)$ \\
\hline Unemployed & $7(12 \%)$ \\
\hline On disability pension & $35(58 \%)$ \\
\hline \multicolumn{2}{|l|}{ Marital status, $n(\%)$} \\
\hline Married/cohabiting & $18(30 \%)$ \\
\hline \multicolumn{2}{|l|}{ Clinical factors } \\
\hline Current use of alcohol (g/day), median (IQR) ${ }^{a}$ & $1.2(0-14.0)$ \\
\hline \multicolumn{2}{|l|}{ Alcohol abuse dg, $n(\%)^{\mathrm{a}}$} \\
\hline Yes & $6(10 \%)$ \\
\hline SOFAS, mean (SD) & $50.7(16.8)$ \\
\hline Onset age (years), mean (SD) & $26.6(6.3)$ \\
\hline Number of hospital treatment days, median (IQR) & $210(84-687)$ \\
\hline \multicolumn{2}{|l|}{ Psychiatric treatment status, $n(\%)$} \\
\hline No treatment contact & $26(43 \%)$ \\
\hline Non-regular outpatient treatment & $7(12 \%)$ \\
\hline Regular outpatient treatment & $22(37 \%)$ \\
\hline Inpatient/institution & $5(8 \%)$ \\
\hline \multicolumn{2}{|l|}{ Diagnosis, $n(\%)$} \\
\hline Schizophrenia & $50(83 \%)$ \\
\hline Schizophreniform disorder & $2(3 \%)$ \\
\hline Schizoaffective disorder & $6(10 \%)$ \\
\hline Delusional disorder & $2(3 \%)$ \\
\hline \multicolumn{2}{|l|}{ Symptom severity } \\
\hline CGI, mean (SD) & $4.5(1.4)$ \\
\hline PANSS, mean $(S D)^{a}$ & $66.6(23.5)$ \\
\hline \multicolumn{2}{|l|}{ Remission, $n(\%)^{\mathrm{a}}$} \\
\hline Yes & $16(28 \%)$ \\
\hline
\end{tabular}

SOFAS: Social and Occupational Functioning Assessment Scale, CGI: Clinical Global Impression, PANSS: Positive and Negative Syndrome Scale, IQR: interquartile range Psychiatric treatment status: non-regular outpatient treatment: contact less than once per month or of unknown frequency, regular outpatient treatment: 1-4 times per month and inpatient/institution: being in psychiatric hospital treatment or sheltered home.

a There were missing data for 1 case in education, 1 case in current use of alcohol,

2 cases in PANSS and 2 cases in remission.

\subsection{The characteristics of medication use}

The lifetime and current use and doses of antipsychotic, benzodiazepine and antidepressant medications are presented in Table 3. During lifetime antipsychotics were used by $98 \%$ of cases, benzodiazepines by $72 \%$ and antidepressants by $42 \%$ and at the time of the study by 85,38 and $22 \%$ respectively. The lifetime and current use and doses of specific medication agents are presented in Supplementary Table 1.

\subsection{The association between lifetime and current benzodiazepine and antidepressant medications and global cognition}

Lifetime cumulative DDD years of benzodiazepines or antidepressants, current DDD ratios and use of benzodiazepines or antidepressants at the time of the study were not significantly associated with global cognition (Table 4). In the post-hoc analyses illustrated in Fig. 1, those with high or medium lifetime DDD years of benzodiazepines had poorer global cognition than those with low lifetime DDD years. However, both low and high lifetime antidepressant doses were associated with better global cognitive performance than medium doses.

\subsection{The association between lifetime and current antipsychotic medication and global cognition}

Being without antipsychotic medication (range 0.9-20.3 years, mean 8.7 years) before the cognitive examination $(n=9)$ was associated with better global cognitive performance $(P=0.012)$, also when adjusted for gender and age of illness onset $(P=0.006)$ or several other covariates, including illness severity measures (Table $5)$. Having long antipsychotic-free periods during treatment, excluding the time of cognitive examination $(n=20)$, was not associated with global cognition (Table 5). A higher proportion of time with antipsychotic use during the illness course, a higher proportion of time on antipsychotic polypharmacy, a higher current DDD ratio of antipsychotic medication and higher current antipsy-

Table 3

Lifetime use and current use of psychiatric medications at 43 years of age in schizophrenia $(n=60)$.

\begin{tabular}{|c|c|c|c|c|}
\hline \multirow[t]{2}{*}{ Medication groups } & \multicolumn{2}{|c|}{ Lifetime use } & \multicolumn{2}{|c|}{ Current use } \\
\hline & $n(\%)$ & $\begin{array}{l}\text { DDD years, } \\
\text { Md (IQR) }\end{array}$ & $n(\%)$ & $\begin{array}{l}\text { DDD ratio, } \\
\text { Md (IQR) }\end{array}$ \\
\hline Antipsychotics & $59(98 \%)$ & $10.4(5.0-29.7)$ & $51(85 \%)$ & $1.2(0.7-2.5)$ \\
\hline Benzodiazepines & $43(72 \%)$ & $4.6(1.2-16.1)$ & $23(38 \%)$ & $1.0(0.4-1.5)$ \\
\hline Antidepressants & $25(42 \%)$ & $3.4(0.8-12.9)$ & $13(22 \%)$ & $1.3(1.0-1.8)$ \\
\hline
\end{tabular}

${ }^{a} \mathrm{Md}$ : median and IQR: interquartile range were calculated for those with lifetime or current use of the specific medication, not for all cases.

Table 4

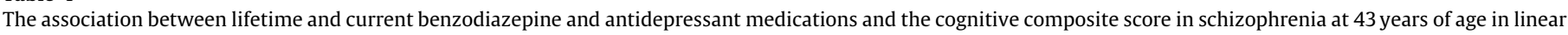
regression analyses.

\begin{tabular}{|c|c|c|c|c|c|c|}
\hline & \multicolumn{3}{|l|}{ Model $^{\mathrm{a}}$} & \multicolumn{3}{|l|}{ Model $^{\mathrm{b}}$} \\
\hline & $\mathrm{B}(\mathrm{SE})^{\mathrm{a}}$ & Beta $^{a}$ & $\operatorname{Sig}^{\mathrm{a}}$ & $\mathrm{B}(\mathrm{SE})^{\mathrm{b}}$ & Beta $^{\mathrm{b}}$ & Sig $^{\mathrm{b}}$ \\
\hline Lifetime DDD years of benzodiazepines ${ }^{c}$ & $-0.16(0.14)$ & -0.18 & 0.278 & $-0.05(0.15)$ & -0.05 & 0.754 \\
\hline Lifetime DDD years of antidepressants ${ }^{c}$ & $0.08(0.21)$ & 0.09 & 0.689 & $0.06(0.20)$ & 0.06 & 0.772 \\
\hline Current DDD ratio of benzodiazepines ${ }^{\mathrm{c}}$ & $-0.37(0.24)$ & -0.41 & 0.115 & $-0.25(0.21)$ & -0.27 & 0.238 \\
\hline Current DDD ratio of antidepressants ${ }^{c}$ & $-0.60(0.42)$ & -0.32 & 0.148 & $-0.78(0.45)$ & -0.42 & 0.081 \\
\hline Current use of benzodiazepines & $-0.15(0.27)$ & -0.07 & 0.571 & $0.08(0.26)$ & 0.04 & 0.761 \\
\hline Current use of antidepressants & $0.48(0.31)$ & 0.20 & 0.127 & $0.19(0.33)$ & 0.08 & 0.561 \\
\hline
\end{tabular}

B: unstandardised regression coefficient, SE: standard error, Beta: standardised regression coefficient, Sig: statistical significance.

a Unadjusted model

b Adjusted for gender and onset age.

c The analyses were completed in a group of those cases that had used the medication and those with no use were excluded. 


\section{Antipsychotics}

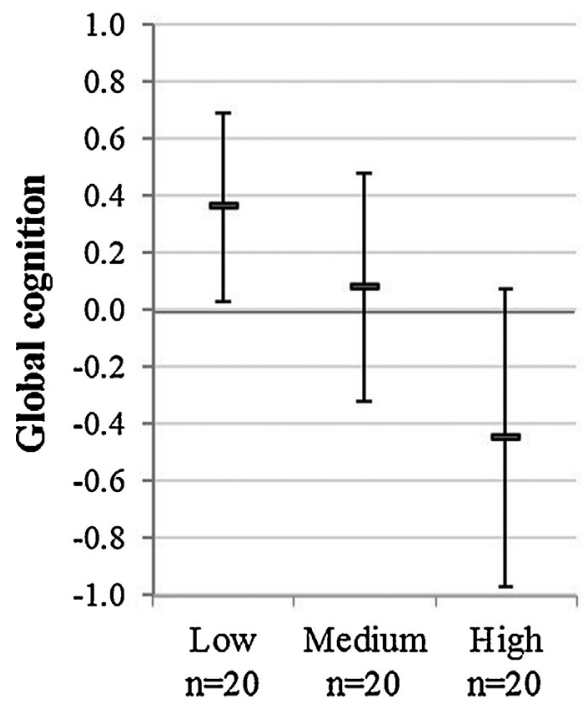

Benzodiazepines

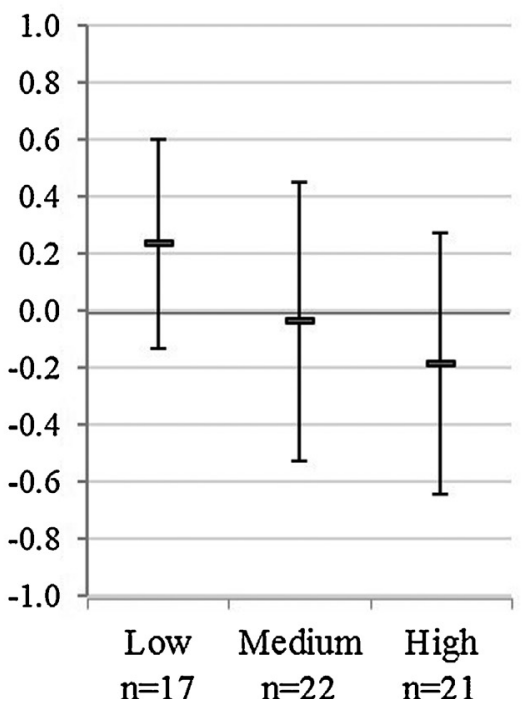

Antidepressants

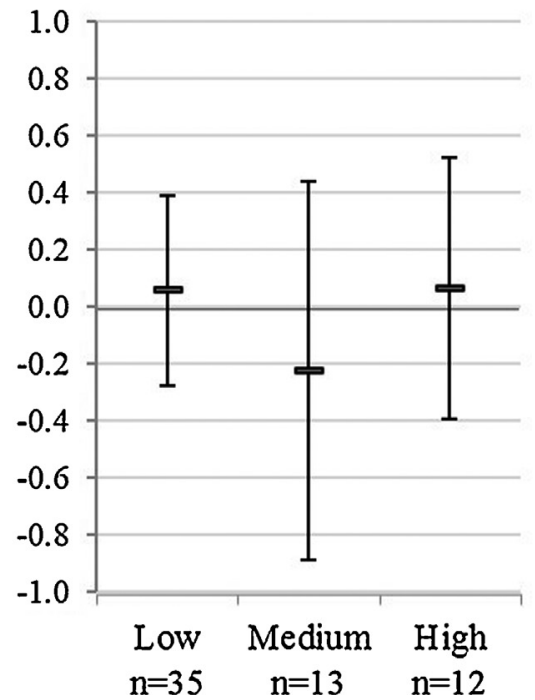

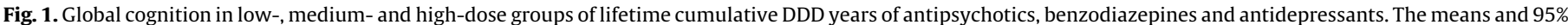

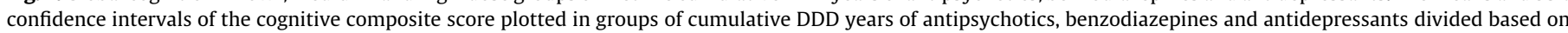

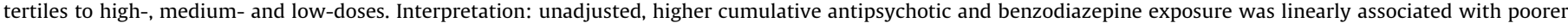
cognition, but both low and high cumulative antidepressant doses were associated with better cognition than medium doses.

chotic polypharmacy had significant unadjusted associations with poorer global cognition, but not when adjusted (Table 5).

Higher lifetime antipsychotic DDD years were significantly associated with poorer global cognition $(P<0.001)$, when adjusted for gender, age of illness onset $(P=0.018)$ and several other covariates (Table 5). The lifetime antipsychotic exposure of those who did not use antipsychotics at the cognitive examination was lower than in the rest of the sample (median 0.3 vs. 14.2 DDD years respectively). In the post hoc analyses, high and medium lifetime DDD years of antipsychotics were associated with poorer global cognition than low lifetime doses (Fig. 1).

\section{Discussion}

\subsection{Main results}

Lifetime and current doses of benzodiazepine and antidepressant medications were not significantly associated with global cognition. Not using antipsychotic medication for a relatively long time before the cognitive examination was associated with better global cognitive performance. However, antipsychotic-free periods of at least one year earlier during treatment were not associated with cognition. Other lifetime trends of antipsychotic use, current

Table 5

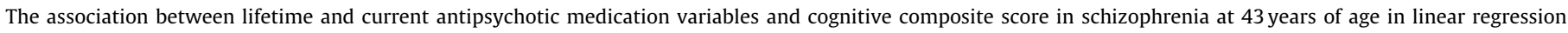
analyses.

\begin{tabular}{|c|c|c|c|c|c|c|c|c|c|c|c|c|}
\hline & \multicolumn{3}{|l|}{ Model $^{\mathrm{a}}$} & \multicolumn{3}{|l|}{ Model $^{\mathrm{b}}$} & \multicolumn{3}{|l|}{ Model $^{\mathrm{c}}$} & \multicolumn{3}{|l|}{ Model $^{\mathrm{d}}$} \\
\hline & $\mathrm{B}(\mathrm{SE})^{\mathrm{a}}$ & Beta $^{a}$ & $\operatorname{Sig}^{\mathrm{a}}$ & $\mathrm{B}(\mathrm{SE})^{\mathrm{b}}$ & Beta $^{\mathrm{b}}$ & $\operatorname{Sig}^{\mathrm{b}}$ & $\mathrm{B}(\mathrm{SE})^{\mathrm{c}}$ & Beta $^{c}$ & $\operatorname{Sig}^{\mathrm{c}}$ & $\mathrm{B}(\mathrm{SE})^{\mathrm{d}}$ & Beta $^{d}$ & $\operatorname{Sig}^{\mathrm{d}}$ \\
\hline Lifetime DDD years of antipsychotics & $0.37(0.11)$ & -0.42 & $<\mathbf{0 . 0 0 1}$ & $0.28(0.12)$ & -0.32 & 0.018 & $-0.34(0.15)$ & -0.39 & 0.020 & $-0.24(0.13)$ & -0.28 & 0.066 \\
\hline Proportion of time with antipsychotic use & $-0.34(0.17)$ & -0.25 & 0.046 & $-0.32(0.16)$ & -0.23 & 0.051 & $-0.31(0.17)$ & -0.23 & 0.066 & $-0.28(0.17)$ & -0.20 & 0.107 \\
\hline $\begin{array}{l}\text { Long antipsychotic-free periods during } \\
\text { treatment }\end{array}$ & $-0.07(0.28)$ & -0.03 & 0.809 & $0.10(0.27)$ & 0.05 & 0.722 & $0.12(0.27)$ & 0.06 & 0.653 & $0.11(0.28)$ & 0.05 & 0.689 \\
\hline $\begin{array}{l}\text { Being without antipsychotic medication } \\
\text { before the cognitive examination }\end{array}$ & $0.89(0.35)$ & 0.32 & 0.012 & $0.90(0.33)$ & 0.32 & 0.006 & $0.98(0.36)$ & 0.35 & 0.007 & $0.81(0.35)$ & 0.29 & 0.021 \\
\hline $\begin{array}{l}\text { Proportion of time on antipsychotic } \\
\text { polypharmacy }\end{array}$ & $-0.35(0.16)$ & -0.28 & 0.029 & $-0.24(0.16)$ & -0.19 & 0.121 & $-0.24(0.18)$ & -0.19 & 0.173 & $-0.20(0.17)$ & -0.16 & 0.235 \\
\hline Current DDD ratio of antipsychotics & $-0.23(0.10)$ & $-\mathbf{0 . 3 0}$ & 0.017 & $-0.14(0.10)$ & -0.18 & 0.181 & $-0.13(0.11)$ & -0.17 & 0.258 & $-0.12(0.10)$ & -0.15 & 0.251 \\
\hline Current antipsychotic polypharmacy & $-0.74(0.30)$ & -0.31 & 0.012 & $-0.49(0.31)$ & -0.21 & 0.110 & $-0.47(0.33)$ & -0.20 & 0.152 & $-0.42(0.33)$ & -0.18 & 0.202 \\
\hline
\end{tabular}

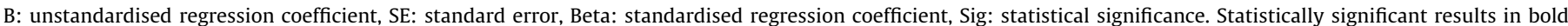

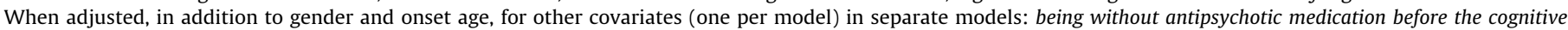

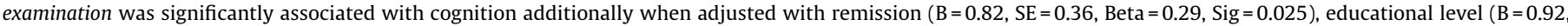

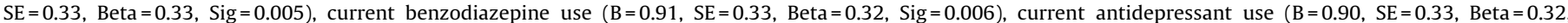

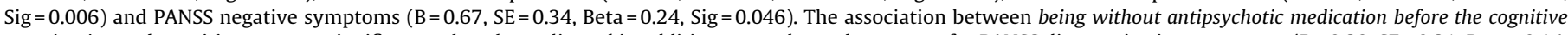

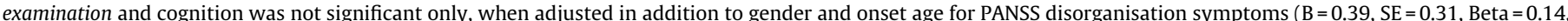

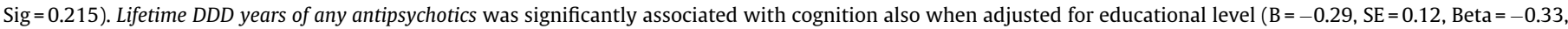

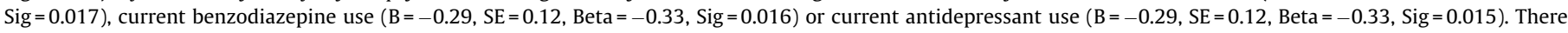
were no other significant associations between the other antipsychotic medication variables and cognition in the models described before.

a Unadjusted model.

b Adjusted for gender and onset age.

c Adjusted for gender, onset age and logarithmic transformation of cumulative lifetime hospital treatment days.

d Adjusted for gender, onset age and PANSS positive symptoms. 
antipsychotic dose or polypharmacy were not significantly associated with cognition in adjusted models.

\subsection{Comparison with previous studies}

Benzodiazepines have been associated with cognitive impairment, both after acute administration [49] and in the longterm treatment in a diagnostically heterogeneous sample [26]. Even with some degree of cognitive recovery, found also in schizophrenia after tapering or withdrawal of long-term benzodiazepine treatment $[27,28]$, the impairments persist [50]. Despite a paucity of studies conducted in schizophrenia and differences in exposure (use of benzodiazepines vs. cumulative dose, withdrawal vs. continued use) and setting (heterogeneous clinical vs. naturalistic sample), our results do not support the earlier findings of the association between use of benzodiazepines and poorer cognition.

The short-term cognitive effects of antidepressants have been positive but clinically negligible $[31,32]$. Not finding an association between cross-sectional or longitudinal, several years of antidepressant exposure and cognition is in line with the previous research.

Our findings could indicate that benzodiazepines and antidepressants do not have strong cognitive effects in schizophrenia, but other explanations are also possible. In the subsample of 43 benzodiazepine and 25 antidepressant users, the lifetime exposure was relatively small (0.25 DDDs of benzodiazepines and 0.19 DDDs of antidepressants per year during the whole illness duration), which may remain under a threshold that could cause permanent, non-reversible cognitive effects. Additionally, most persons in our sample had used several medications and antipsychotics more than other medications, making it difficult to separate the effects of benzodiazepines and antidepressants.

Antipsychotics have minimal cognitive effects in schizophrenia during the first years of treatment [7]. Antipsychotic polypharmacy has been connected with both negative [19] and neutral cognitive effects [51], but not with higher mortality than antipsychotic monotherapy [52]. A number of studies have documented associations between high-dose, long-term antipsychotic exposure and changes in the brain volume [53-55], functioning [56] and cognition [16,57]. The association between higher lifetime antipsychotic DDD years and poorer cognition was not a novel finding, as we reported it in our prior study using chlorpromazine equivalent dose-years [17]. The method of measuring drug exposure did not significantly influence the main results, even though discrepancy has been found between chlorpromazine and DDD-equivalence estimations [58].

The finding indicating that being without antipsychotics for a relatively long time before the cognitive examination is associated with better cognitive functioning, but antipsychotic-free periods at any other time during the treatment were not, can be seen to further support the view that antipsychotics do influence cognitive functioning in schizophrenia, but their cognitive effects may not be irreversible.

Earlier studies have also identified a subpopulation of persons with schizophrenia who manage for many years with a lower dose or without antipsychotic medication and have markers of less severe illness [59] or better functional outcome [60]. In the NFBC 1966 being antipsychotic-free [61], having low cumulative lifetime antipsychotic dose or no drug-free periods of at least a month have also been associated with better functioning in midlife schizophrenia [37]. It is also likely that the persons in the current study $(n=9)$, who managed for a long time (some for several years) without antipsychotics belong to this subgroup with a less severe illness course, perhaps a lower relapse risk and better preserved cognitive functioning. Also their lifetime exposure to antipsychotics was significantly lower than the exposure of the rest of the sample. Thus the finding of lower lifetime dose and better cognition may be related to a group of persons who do not use antipsychotics at the time of cognitive examination.

Most patients with schizophrenia have a significantly higher relapse risk without antipsychotic medication [2,62] and recurrent or persistent psychosis has been posited to be detrimental to cognition [63]. Treatment algorithms recommend maintenance antipsychotic treatment especially with multiple psychotic episodes, but also give room to controlled dose tapering and discontinuation strategies [2].

\subsection{Theoretical discussion}

The cognitive effects of pharmacological agents rise from their potential to disrupt neurotransmission in areas of the brain responsible for cognitive functioning [49]. The cholinergic system projecting to the cortex and hippocampus is involved with memory, perception and attention. Anticholinergic qualities of medications, including many antipsychotic and antidepressant agents, impair cognitive functions and alterations in cholinergic function may mediate even longer-term adverse cognitive effects [64]. The short-term and long-term negative cognitive effects of benzodiazepines may relate to the potentiation of $y$-aminobutyric acid (GABA), the major inhibitory neurotransmitter in the brain [65]. The properties of antipsychotics, especially D2 antagonism with high-potency or high-occupancy binding due to high-dose exposure and glutaminergic inhibition by $5-\mathrm{TH}-2 \mathrm{~A}$ antagonism have been hypothesised to worsen the mesocortical hypodopaminergic state behind negative and cognitive symptoms in schizophrenia [66-68].

Antidepressants have been theorised to improve cognition via enhanced serotonergic, adrenergic and dopaminergic transmission, based on the mechanisms of specific agents, and less expected benefits with agents of higher anticholinergic activity, such as tricyclic antidepressants, but no relevant improvement has been observed adjunctive to antipsychotic treatment [31]. In the longterm use of benzodiazepines the development of tolerance to sedative effects [69] could possibly reduce the cognitive effects.

\subsection{Strengths and limitations}

The strength of this study is the naturalistic, non-selected sample with wide-ranging, reliable, prospective information based on interviews, medical records and linkage to register data. The longitudinal data on lifetime exposure to and timing of use of psychiatric medications are unique. Utilising DDD equivalents available for all medications instead of chlorpromazine equivalents has the benefit that they are more frequently updated and based on wider usage data [58]. Selection bias in this epidemiologically sound sample is minimised in comparison with selected, clinical populations and the results may be more generalisable to real-world schizophrenia. The attrition bias was also analysed thoroughly and it is unlikely that it would affect the results [16].

A limitation is the comparatively small sample size, especially in the subgroups of benzodiazepine and antidepressant users, which limits the power to detect the effects of medication and rule out type II error. Because of multiple medication variables analysed, the likelihood that some of the significant results may be chance findings can increase. Adherence could also reduce the reliability of the medication data. Access to medical records and not only registers on prescriptions or purchases has enabled taking known antipsychotic-free periods and measures of adherence into account resulting in considerably reliable cumulative antipsychotic variables accepted before in several peer-reviewed publications $[16,17,37,55]$. It would be relevant to analyse the cognitive effects 
of individual medications, instead of groups with heterogeneous mechanisms of action, and other psychiatric medications, such as mood stabilisers, but the sample size and use of many different medications by the same person during their lifetime did not allow for more detailed analyses. Two persons had used up to 14 different antipsychotic agents during their lives [16]. Also global cognitive performance may have been too insensitive to detect the effects of medications.

Naturalistic studies are limited in showing causality, yet they may be optimal and the only realistic option to study long-term exposure to medications [33]. Longitudinal assessment of global cognition and symptoms, of which we do not have available data, could have enabled a more refined analysis of cognitive trajectories related to the illness process and other factors such as treatment. However, owing to our extensive database, we were able to control for a variety of most potential confounders associated with illness duration and both longitudinal and current severity at the time of the study and significantly reduce the risk of residual confounding. In this sample, transversal measurements reflect also longitudinal course: key areas of cognition [70] and antipsychotic medication [37] were quite stable in midlife. It is still possible that higher antipsychotic doses are given to those with a more severe or earlier onset illness and mark this more unfavourable illness course rather than cause poorer cognition. Similarly, managing without antipsychotics for many years may be a marker of a milder illness, which is also associated with preserved cognition. The possibility that long-term high-dose antipsychotic treatment could worsen cognitive deficits related to schizophrenia, supported by cumulating findings, should also be taken seriously.

Interpretation of the findings of this study concerning the safety of long-term benzodiazepine and antidepressant use that was very low in our sample or risks and benefits of antipsychotic discontinuation should be cautious. Further study in larger populations of the long-term exposure to and optimal treatment strategies of psychiatric medications in schizophrenia is needed for clinical implications as well as identifying markers of a subpopulation that may manage with smaller doses or even without antipsychotic medication.

\section{Conclusions}

Polypharmacy continues to be a common practice in the treatment of schizophrenia and regular critical evaluation of medication is required to reduce it. To our knowledge, this is the first report on the association between lifetime cumulative benzodiazepine and antidepressant exposures and cognition in midlife schizophrenia. Based on these naturalistic data, low exposure to adjunctive benzodiazepine and antidepressant medications does not seem to greatly affect cognition nor explain the cognitive effects of antipsychotic medication in schizophrenia.

\section{Financial support}

This work was supported by the Academy of Finland [grant numbers 278 286, 268 336], the Sigrid Jusélius Foundation, the Brain \& Behavior Research Foundation, the Jalmari and Rauha Ahokas Foundation, the Finnish Cultural Foundation Lapland Regional Fund, the Northern Finland Health Care Support Foundation, the scholarship Fund of the University of Oulu Tyyni Tani Fund, the Foundation for Psychiatric Research and the Orion Research Foundation sr. J.H.B. was an employee of Cambridge Cognition. The funding bodies had no further role in study design; in the collection, management, analysis and interpretation of data; in the preparation, review or approval of the manuscript; or in the decision to submit the paper for publication.

\section{Disclosure of interest}

J.H. Barnett is an employee of and shareholder in Cambridge Cognition, a cognitive assessment company. P.B. Jones has been a member of Roche and Otsuka Scientific Advisory Boards 20122014.

A.P. Hulkko, G.K. Murray, J. Moilanen, M. Haapea, I. Rannikko, S. Huhtaniska, M.K. Isohanni, E. Jääskeläinen and J. Miettunen declare that they have no competing interest.

\section{Acknowledgements}

We would like to acknowledge all the participants of this study and researchers collecting the data.

\section{Appendix A. Supplementary data}

Supplementary data associated with this article can be found, in the online version, at http://dx.doi.org/10.1016/j.eurpsy.2017.06. 004.

\section{References}

[1] National Institute for Health and Care Excellence. Psychosis and schizophrenia in adults: treatment and management NICE Clinical Guideline, 178. 2014.

[2] Lehman AF, Lieberman JA, Dixon LB, McGlashan TH, Miller AL, Perkins DO, et al. Practice guideline for the treatment of patients with schizophrenia, 2nd ed., American Psychiatric Association; 2010.

[3] Correll CU, Rummel-Kluge C, Corves C, Kane JM, Leucht S. Antipsychotic combinations vs monotherapy in schizophrenia: a meta-analysis of randomized controlled trials. Schizophr Bull 2009;35:443-57.

[4] Volz A, Khorsand V, Gillies D, Leucht S. Benzodiazepines for schizophrenia. Cochrane Database Syst Rev 2007;(1):CD006391.

[5] Rummel C, Kissling W, Leucht S. Antidepressants as add-on treatment to antipsychotics for people with schizophrenia and pronounced negative symptoms: a systematic review of randomized trials. Schizophr Res 2005;80:85-97.

[6] Reichenberg A, Caspi A, Harrington H, Houts R, Keefe RSE, Murray RM, et al. Static and dynamic cognitive deficits in childhood preceding adult schizophrenia: a 30-year study. Am J Psychiatry 2010;167(2):160-9.

[7] Szöke A, Trandafir A, Dupont ME, Méary A, Schürhoff F, Leboyer M. Longitudinal studies of cognition in schizophrenia: meta-analysis. Br J Psychiatry 2008;192:248-57.

[8] Bozikas VP, Andreou C. Longitudinal studies of cognition in first episode psychosis: a systematic review of the literature. Aust New Zealand J Psychiatry 2011;45(2):93-108

[9] Zipursky RB, Reilly TJ, Murray RM. The myth of schizophrenia as a progressive brain disease. Schizophr Bull 2013;39(6):1363-72.

[10] Irani F, Kalkstein S, Moberg EA, Moberg PJ. Neuropsychological performance in older patients with schizophrenia: a meta-analysis of cross-sectional and longitudinal studies. Schizophr Bull 2011;37(6):1318-26.

[11] Rajji TK, Miranda D, Mulsant BH. Cognition, function, and disability in patients with schizophrenia: a review of longitudinal studies. Can J Psychiatry 2014;59:13-7.

[12] Désaméricq G, Schurhoff F, Meary A, Szöke A, Macquin-Mavier I, Bachoud-Lévi AC, et al. Long-term neurocognitive effects of antipsychotics in schizophrenia: a network meta-analysis. Eur J Clin Pharmacol 2014;70:127-34.

[13] Woodward ND, Purdon SE, Meltzer HY, Zald DH. A meta-analysis of neuropsychological change to clozapine, olanzapine, quetiapine, and risperidone in schizophrenia. Int J Neuropsychopharmacol 2005;8:457-72.

[14] Mishara AL, Goldberg TE. A meta-analysis and critical review of the effects of conventional neuroleptic treatment on cognition in schizophrenia: opening a closed book. Biol Psychiatry 2004:55:1013-22.

[15] Goldberg TE, Keefe RSE, Goldman RS, Robinson DG, Harvey PD. Circumstances under which practice does not make perfect: a review of the practice effect literature in schizophrenia and its relevance to clinical treatment studies. Neuropsychopharmacology 2010;35:1053-62.

[16] Husa AP, Moilanen J, Murray GK, Marttila R, Haapea M, Rannikko I, et al. Lifetime antipsychotic medication and cognitive performance in schizophrenia at age 43 years in a general population birth cohort. Psychiatry Res 2017;247:130-8.

[17] Husa AP, Rannikko I, Moilanen J, Haapea M, Murray GK, Barnett J, et al. Lifetime use of antipsychotic medication and its relation to change of verbal learning 
and memory in midlife schizophrenia - An observational 9-year follow-up study. Schizophr Res 2014;158:134-41.

[18] Élie D, Poirier M, Chianetta JM, Durand M, Grégoire CA, Grignon S. Cognitive effects of antipsychotic dosage and polypharmacy: a study with the BACS in patients with schizophrenia and schizoaffective disorder. J Psychopharmacol 2010;24:1037-44.

[19] Hori H, Noguchi H, Hashimoto R, Nakabayashi T, Omori M, Takahashi S, et al. Antipsychotic medication and cognitive function in schizophrenia. Schizophr Res 2006:86:138-46.

[20] Torniainen M, Suvisaari J, Partonen T, Castaneda AE, Kuha A, Suokas J, et al Cognitive impairments in schizophrenia and schizoaffective disorder: relationship with clinical characteristics. J Nerv Ment Dis 2012;200:316-22.

[21] Kawai N, Yamakawa Y, Baba A, Nemoto K, Tachikawa H, Hori T, et al. High-dose of multiple antipsychotics and cognitive function in schizophrenia: the effect of dose-reduction. Prog Neuropsychopharmacol Biol Psychiatry 2006;30: 1009-14.

[22] Takeuchi H, Suzuki T, Remington G, Bies RR, Abe T, Graff-Guerrero A, et al. Effects of risperidone and olanzapine dose reduction on cognitive function in stable patients with schizophrenia: an open-label, randomized, controlled, pilot study. Schizophr Bull 2013;39:993-8.

[23] Fontanella CA, Campo JV, Phillips GS, Hiance-Steelesmith DL, Sweeney HA, Tam K, et al. Benzodiazepine use and risk of mortality among patients with schizophrenia: a retrospective longitudinal study. J Clin Psychiatry 2016;77:661-7.

[24] Dold M, Li C, Gilliesc D, Leucht S. Benzodiazepine augmentation of antipsychotic drugs in schizophrenia: a meta-analysis and Cochrane review of randomized controlled trials. Eur Neuropsychopharmacology 2013;23: 1023-33.

[25] Tiihonen J, Mittendorfer-Rutz E, Torniainen M, Alexanderson K, Tanskanen A. Mortality and cumulative exposure to antipsychotics, antidepressants, and benzodiazepines in patients with schizophrenia: an observational follow-up study. Am J Psychiatry 2016;173:600-6.

[26] Barker MJ, Greenwood KM, Jackson M, Crowe SF. Cognitive effects of long-term benzodiazepine use: a meta-analysis. CNS Drugs 2004;18:37-48.

[27] Kitajima R, Miyamoto S, Tenjin T, Ojima K, Ogino S, Miyake N, et al. Effects of tapering of long-term benzodiazepines on cognitive function in patients with schizophrenia receiving a second-generation antipsychotic. Prog Neuropsychopharmacol Biol Psychiatry 2012;36:300-6.

[28] Baandrup L, Fagerlund B, Glenthoj B. Neurocognitive performance, subjective well-being, and psychosocial functioning after benzodiazepine withdrawal in patients with schizophrenia or bipolar disorder: a randomized clinical trial of add-on melatonin versus placebo. Eur Arch Psychiatry Clin Neurosci 2017;267:163-71.

[29] Whitehead C, Moss S, Cardno A, Lewis G. Antidepressants for the treatment of depression in people with schizophrenia: a systematic review. Psychol Med 2003;33:589-99.

[30] Singh SP, Singh V, Kar N, Chan K. Efficacy of antidepressants in treating the negative symptoms of chronic schizophrenia: meta-analysis. Br J Psychiatry 2010;197:174-9.

[31] Vernon JA, Grudnikoff E, Seidman AJ, Frazier TW, Vemulapalli MS, Pareek P, et al. Antidepressants for cognitive impairment in schizophrenia - a systematic review and meta-analysis. Schizophr Res 2014;159:385-94.

[32] Terevnikov V, Joffe G, Stenberg JH. Randomized controlled trials of add-on antidepressants in schizophrenia. Int J Neuropsychopharmacol 2015;18:1-14.

[33] Wang PS, Brookhart AM, Ulbricht C, Schneeweiss S. The pharmacoepidemiology of psychiatric medications. In: Tsuang $\mathrm{M}$, Tohen $\mathrm{M}$, Jones $\mathrm{P}$, editors. Textbook in psychiatric epidemiology. 3rd ed., Hoboken, New Jersey, USA: Wiley-Blackwell; 2011. p. 155-65.

[34] Jääskeläinen E, Haapea M, Rautio N, Juola P, Penttilä M, Nordström T, et al. Twenty years of schizophrenia research in the Northern Finland birth cohort 1966: a systematic review. Schizophr Res Treatment 2015. http://dx.doi.org 10.1155/2015/524875 [Article ID 524875, 12 pages].

[35] Rantakallio P. Groups at risk in low birth weight infants and perinatal mortality. Acta Paediatr Scand 1969;Suppl. 193:1-71

[36] Haapea M, Miettunen J, Lindeman S, Joukamaa M, Koponen H. Agreement between self-reported and pharmacy data on medication use in the Northern Finland 1966 Birth Cohort. Int J Methods Psychiatr Res 2010;19:88-96.

[37] Moilanen JM, Haapea M, Jääskeläinen E, Veijola JM, Isohanni MK, Koponen HJ, et al. Long-term antipsychotic use and its association with outcomes in schizophrenia-the Northern Finland Birth Cohort 1966. Eur Psychiatry 2016;36:7-14.

[38] Nykänen S, Puska V, Tolonen JP, Salo H, Isohanni M, Koponen H, et al. Use of psychiatric medications in schizophrenia and other psychoses in a general population sample. Psychiatry Res 2016;235:160-8.

[39] Glahn DC, Cannon TD, Gur RE, Ragland JD, Gur RC. Working memory constrains abstraction in schizophrenia. Biol Psychiatry 2000;47:34-42.

[40] Delis DC, Kramer JH, Kaplan E, Ober BA. California Verbal Learning Test. New York: Psychological Corporation; 1987.

[41] Glahn DC, Gur RC, Ragland JD, Censits DM, Gur RE. Reliability, performance characteristics, construct validity, and an initial clinical application of a visual object learning test (VOLT). Neuropsychology 1997;11:602-12.

[42] Lezak MD, Howieson DB, Loring DW. Neuropsychological assessment, 4th ed. Oxford University Press, Inc; 2004. p. 2004

[43] Wechsler D. WMS-III - Wechsler Memory Scale, 3rd ed., New York: The Psychological Corporation. Helsinki, Finland: psykologien Kustannus Oy 2008.
[44] Wechsler D. Wechsler Adult Intelligence Scale, Third edition: manual, Helsinki, Finland: Psykologien Kustannus Oy; 2005.

[45] WHO Collaborating Centre for Drug Statistics Methodology. Guidelines for ATC classification and DDD assignment 2016. Oslo; 2016.

[46] van der Gaag M, Hoffman T, Remijsen M, Hijman R, de Haan L, van Meijel B, et al. The five-factor model of the Positive and Negative Syndrome Scale II: a ten-fold cross-validation of a revised model. Schizophr Res 2006;85(13):280-7.

[47] Rubin D. Multiple imputation for nonresponse in surveys. New York: Wiley; 1987.

[48] IBM Corp. IBM SPSS Statistics for Windows, Version 24. 0. Armonk, NY: IBM Corp; 2016.

[49] Tannenbaum C, Paquette A, Hilmer S, Holroyd-Leduc J, Carnahan R. A systematic review of amnestic and non-amnestic mild cognitive impairment induced by anticholinergic, antihistamine, GABAergic and opioid drugs. Drugs Aging 2012;29:639-58.

[50] Barker MJ, Greenwood KM, Jackson M, Crowe SF. Persistence of cognitive effects after withdrawal from long-term benzodiazepine use: a meta-analysis. Arch Clin Neuropsychol 2004;19:437-54.

[51] Kontis D, Theochari E, Kleisas S, Kalogerakou S, Andreopoulou A, Psaras R, et al. Doubtful association of antipsychotic polypharmacy and high dosage with cognition in chronic schizophrenia. Prog Neuropsychopharmacol Biol Psychiatry 2010;34:1333-41.

[52] Tiihonen J, Suokas JT, Suvisaari JM, Haukka J, Korhonen P. Polypharmacy with antipsychotics, antidepressants, or benzodiazepines and mortality in schizophrenia. Arch Gen Psychiatry 2012;69:476-83.

[53] Andreasen NC, Liu D, Ziebell S, Vora A, Ho BC. Relapse duration, treatment intensity, and brain tissue loss in schizophrenia: a prospective longitudinal MRI study. Am J Psychiatry 2013;170:609-15.

[54] Fusar-Poli P, Smieskova R, Kempton MJ, Ho BC, Andreasen NC, Borgwardt S. Progressive brain changes in schizophrenia related to antipsychotic treatment? A meta-analysis of longitudinal MRI studies. Neurosci Biobehav R 2013;37:1680-91.

[55] Veijola J, Guo JY, Moilanen JS, Jääskeläinen E, Miettunen J, Kyllönen M, et al. Longitudinal changes in total brain volume in schizophrenia: relation to symptom severity, cognition and antipsychotic medication. Plos One 2014;9(7):e101689. http://dx.doi.org/10.1371/journal.pone.0101689.

[56] Abbott CC, Jaramillo A, Wilcox CE, Hamilton DA. Antipychotic drug effects in schizophrenia: a review of longitudinal fMRI investigations and neural interpretations. Curr Med Chem 2013;20:428-37.

[57] Knowles EE, David AS, Reichenberg A. Processing speed deficits in schizophrenia: reexamining the evidence. Am J Psychiatry 2010;167:828-35.

[58] Rijcken CAW, Monster TBM, Brouwers JRBJ, de Jong-van den Berg LTW. Chlorpromazine equivalents versus defined daily doses: how to compare antipsychotic drug doses? J Clin Psychopharmacol 2003;23:657-9.

[59] Harrow M, Jobe TH, Faull RN. Does treatment of schizophrenia with antipsychotic medications eliminate or reduce psychosis? A 20-year multi-follow-up study. Psychol Med 2014;44:3007-16.

[60] Wunderink L, Nieboer RM, Wiersma D, Sytema S, Nienhuis FJ. Recovery in remitted first-episode psychosis at 7 years of follow-up of an early dose reduction/discontinuation or maintenance treatment strategy: long-term follow-up of a 2-year randomized clinical trial. JAMA Psychiatry; 2013;70: 913-20.

[61] Moilanen J, Haapea M, Miettunen J, Jääskeläinen E, Veijola J, Isohanni M, et al. Characteristics of subjects with schizophrenia spectrum disorder with and without antipsychotic medication-a 10-year follow-up of the Northern Finland 1966 Birth Cohort study. Eur Psychiatry 2013;28:53-8.

[62] Winton-Brown TT, Elanjithara T, Power P, Coentre R, Blanco-Polaina P, McGuire P. Five-fold increased risk of relapse following breaks in antipsychotic treatment of first episode psychosis. Schizophr Res 2017;179:50-6.

[63] Harvey PD, Loewenstein DA, Czaja SJ. Hospitalization and psychosis: influences on the course of cognition and everyday functioning in people with schizophrenia. Neurobiol Dis 2013;53:18-25.

[64] Terry AV, Mahadik SP. Time-dependent cognitive deficits associated with first and second generation antipsychotics: cholinergic dysregulation as a potential mechanism. J Pharmacol Exp Ther 2007;320:961-8.

[65] Nestler EJ, Hyman SE, Malenka RC. Molecular neuropharmacology: a foundation for clinical neuroscience, 2nd ed., New York: The McGraw-Hill Companies; 2009.

[66] Liemburg EJ, Knegtering H, Klein HC, Kortekaas R, Aleman A. Antipsychotic medication and prefrontal cortex activation: a review of neuroimaging findings. Eur Neuropsychopharmacol 2012;22:387-400.

[67] Sakurai H, Bies RR, Stroup ST, Keefe RS, Rajji TK, Suzuki T, et al. Dopamine D2 receptor occupancy and cognition in schizophrenia: analysis of the CATIE data. Schizophr Bull 2013;39:564-74

[68] Stahl SM. Antipsychotics and mood stabilizers: Stahl's essential psychopharmacology, 3rd ed., New York: Cambridge University Press; 2008.

[69] Vinkers CH, Olivier B. Mechanisms underlying tolerance after long-term benzodiazepine use: a future for subtype-selective GABAA Receptor modulators? Adv Pharmacol Sci 2012. http://dx.doi.org/10.1155/2012/ 416864416864 [Article ID 416864].

[70] Rannikko I, Haapea M, Miettunen J, Veijola J, Murray GK, Barnett JH, et al. Changes in verbal learning and memory in schizophrenia and non-psychotic controls in midlife: a nine-year follow-up in the Northern Finland Birth Cohort study 1966. Psychiatry Res 2015;228:671-9. 


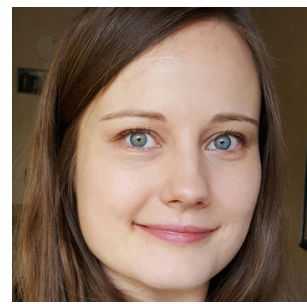

Anja P. Hulkko (née Husa), M.D., is a Resident in Psychiatry and a Ph.D. Student in the Research Unit of Clinical Neuroscience, University of Oulu, Finland and Medical Research Center Oulu, Oulu University Hospital and University of Oulu, Finland. She is also training to be a cognitive analytic psychotherapist in the University of Helsinki, Finland. Her research interests include psychiatric epidemiology, psychopharmacology, neurocognition, and treatment of schizophrenia. E-mail: anja.husa@student.oulu.fi.

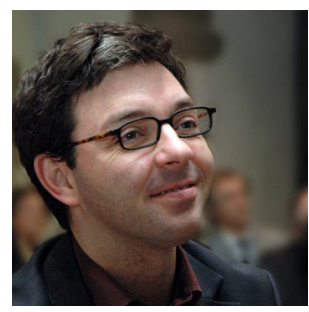

Graham K. Murray, M.D., Ph.D., is a University Lecturer in the Department of Psychiatry, University of Cambridge. He trained in London and Cambridge in the UK, and Oulu in Finland. He researches the causes and treatments of mental disorder, with a focus on psychosis and depression. His main research techniques are cognitive and behavioural neuroscience, and cognitive developmental epidemiology. E-mail: gm285@cam.ac.uk.

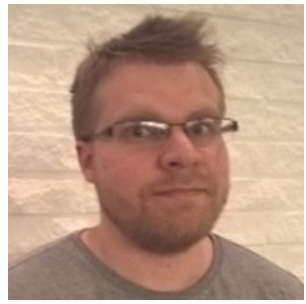

Jani M. Moilanen, M.D., Ph.D., works as a resident in psychiatry in outpatient care in Kempele, Finland. He has been part of the NFBC 1966 study group since 2007 and has special interest in psychotropic medication. E-mail: jani.moilanen@kempele.fi.

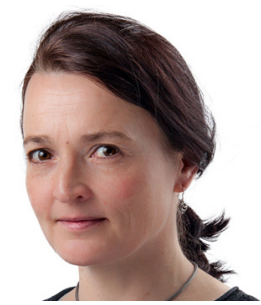

Marianne Haapea, MSc degree in statistics (1988), $\mathrm{PhD}$ degree in psychiatry (2010), from the University of Oulu, Finland. She is currently working as a research doctor in the Center for Life Course Health Research, University of Oulu, and as a biostatistician in the department of Diagnostic Radiology, Oulu University Hospital. Her main research area is cognition and medication in schizophrenia. Her research interests include non-response and information bias, and reliability and generalizability of research findings, in population-based data. E-mail: marianne. haapea@oulu.fi.

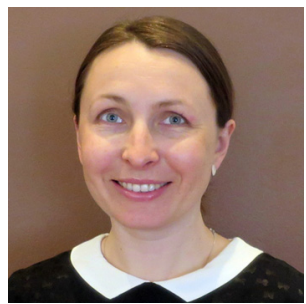

Irina Rannikko, Ph.D., is a Clinical Neuropsychologist and cognitive researcher at the Center for Life Course Health Research, University of Oulu, Finland, with experience in training and supervising neuropsychological research. Her broader interests include life course developmental and family-related factors within different condition of cognitive ability (especially in executive functioning and memory), and role of risk and protective factors for favourable cognitive lifelong development. In Post Doc research, her longterm goal is to improve the understanding of midlife changes in human cognitive functioning and related predictors and develop effective prevention and interventions for cognitive impairment in general population and schizophrenia.

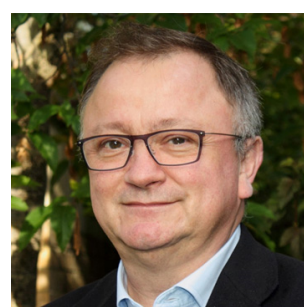

Peter B. Jones is Professor of Psychiatry at the University of Cambridge. His research encompasses the life course epidemiology of major mental illnesses, particularly the psychoses, and he has collaborated with colleagues at the University of Oulu and the North Finland birth cohorts on this topic since 1993. He is an NIHR Senior Investigator and Thompson Reuters highly cited researcher in psychiatry and psychology. E-mail: pbj21@cam.ac.uk.

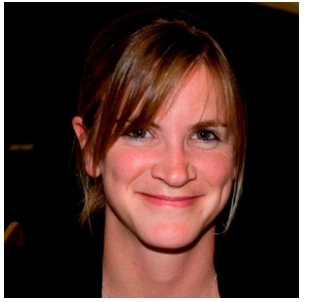

Jennifer H. Barnett, Ph.D. My academic background is in cognitive psychology and epidemiology, with a focus on genetic and environmental influences on cognition. I read Experimental Psychology at Oxford University before moving to the Department of Psychiatry at the University of Cambridge for my $\mathrm{PhD}$ and post-doctoral work. Since November 2008, I have worked primarily at Cambridge Cognition, a UK technology company involved in the design of cognitive and clinical testing tools and their use in research, clinical trials and healthcare. I remain actively involved in academic research through the Universities of Cambridge, Oulu and Bristol. E-mail: jhb32@cam.ac.uk.

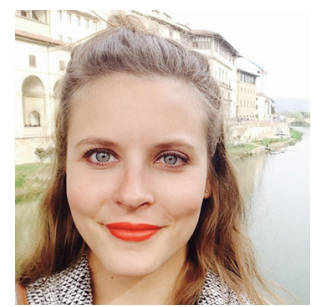

Sanna Huhtaniska is a Ph.D. Student and M.D. since March 2015. Since then, she has worked as a general practitioner and is currently working full-time with her thesis in the Center for Life Course Health Research, University of Oulu. She is interested in brain structure and functioning in psychotic disorders. Email: sanna.huhtaniska@oulu.fi.

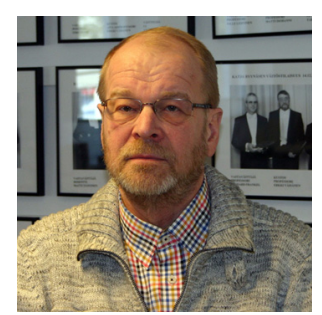

Matti Isohanni, Professor (emeritus), (born 1945) has been the chairman and Professor of psychiatry in the University of Oulu 1994-2013. His scientific activities have been focused first on the development of therapeutic communities for psychosis patients and elderly people. His main area of research has been epidemiological. He has been responsible for the psychiatric follow-up of the extensive Northern Finland 1966 Birth Cohort Study, and analysing from it the early predictors of schizophrenia and other psychoses, as well as life span brain alterations, medications, and other outcomes. He is the author in over 230 international peer-reviewed articles. Email: matti.isohanni@oulu.fi.

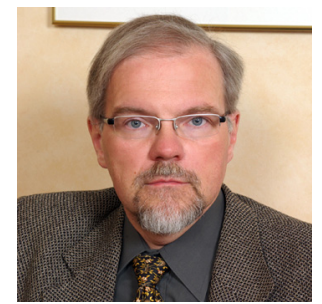

Hannu Koponen, M.D., Ph.D., has been working as Professor in Old Age Psychiatry in the University of Helsinki, and Helsinki University Hospital since 2013. His scientific activity has started in the 1980 s and the topics relate to psychiatric epidemiology, schizophrenia and psychopharmacology, and he has authored over 170 original papers in these fields. E-mail: hannu.j.koponen@hus.fi.

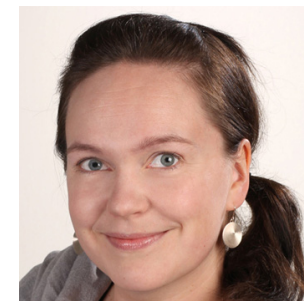

Erika Jääskeläinen, M.D., Ph.D., Adjunct Professor, works as a researcher in the University of Oulu and as a psychiatrist in Caritas Medical Center and Oulu University Hospital. She has studied schizophrenia for 16 years, and she is especially interested on epidemiology, outcomes, cognition, and treatment in psychoses. E-mail: erika.jaaskelainen@oulu.fi.

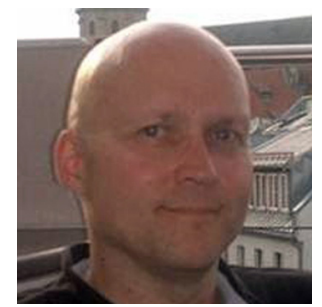

Jouko Miettunen is a Professor of clinical epidemiology at the Center for Life Course Health Research, University of Oulu, Finland. He is also currently working as Academy Research Fellow on risk factors for schizophrenia. He has a M.Sc. degree in statistics from the University of Oulu, Finland, M.Phil. degree in epidemiology from the University of Cambridge, UK, and Ph.D. in psychiatry from the University of Oulu, Finland. He has over 220 publications, especially on schizophrenia, temperament and medical statistics. E-mail: jouko.miettunen@oulu.fi. 